\title{
PENGARUH KUALITAS PELAYANAN TERHADAP KEPUASAN PELANGGAN DI PT HUTCHISON 3 INDONESIA
}

\author{
Mayer Abadi Siregar \\ STIE Unisadhuguna Jakarta, Indonesia \\ Email : mayer_bd@yahoo.com
}

\begin{abstract}
Abstrak
Pendahuluan : Kualitas layanan kepada pelanggan memiliki peran yang sangat penting. PT Hutchison Tri Indonesia yang bergerak di bidang jasa telekomunikasi, maka untuk meningkatkan kualitas bentuk layanan manajemen untuk 3Store, penerapan konsep baru tersebut masih belum pasti apakah dapat meningkatkan kualitas layanan atau sebaliknya. Dengan konsep yang sangat berbeda menimbulkan pro dan kontra dari pelanggan. Masalah yang harus dipelajari adalah "Apakah kualitas layanan mempengaruhi kepuasan pelanggan di 3Store Ambasador dalam hal lima variabel kualitas layanan yaitu: bukti fisik, keandalan, jaminan, responsivitas, dan empati.

Tujuan : Tujuan dari penelitian ini adalah untuk menentukan kualitas layanan dengan konsep baru yang mempengaruhi kepuasan pelanggan 3Store Ambasador.

Metode : Hipotesis dalam penelitian ini kualitas layanan yang terdiri dari variabel bukti fisik, keandalan, jaminan, responsivitas, dan empati memiliki efek signifikan pada kepuasan pelanggan 3Store Ambasador. Metode pengumpulan data untuk menguji hipotesis menggunakan kuesioner yang ditujukan kepada 100 responden pelanggan 3Store Ambasador.

Hasil : Berdasarkan hasil t-test, setiap variabel independen yaitu bukti fisik, keandalan, responsif, jaminan, dan empati memiliki efek positif pada kepuasan pelanggan variabel (Y), yang paling berpengaruh adalah variabel jaminan, kesimpulan dari hipotesis bernomor ditolak dan hipotesis nol diterima.

Kesimpulan : Adanya pengaruh secara signifikan antara kualitas pelayanan dengan konsep baru terhadap kenyamanan pelanggan dan kepuasan pelanggan. Perubahan konsep ini berhasil walaupun diperkecil dari segi tampilan tetapi pelanggan tetap merasa puas dengan kualitas pelayanannya.
\end{abstract}

Kata kunci : Kualitas Layanan, Kepuasan Konsumen, 3Store Ambasador

\section{Abstract}

Introduction: The quality of service to customers has a very important role. PT Hutchison Tri Indonesia engaged in telecommunication services, so to improve the quality of management service forms for 3Store, the implementation of the new concept is still uncertain whether it can improve the quality of service or vice versa. With very different concepts give rise to the pros and cons of the customer. The issue to be studied is "Does service quality affect customer satisfaction at 3Store Ambassador in terms of five service quality variables: physical evidence, reliability, assurance, responsiveness, and empathy.

Objective: The purpose of this study was to determine the quality of service with a new concept that affects customer satisfaction of 3Store Ambassador.

Method: Hypotheses in this study of service quality consisting of variables of physical evidence, reliability, assurance, responsiveness, and empathy have a 
significant effect on customer satisfaction of 3Store Ambassador. The data collection method for testing hypotheses using questionnaires addressed to 100 respondents to 3Store Ambasador customers.

Results: Based on t-test results, each independent variable i.e. physical evidence, reliability, responsiveness, assurance, and empathy has a positive effect on customer satisfaction variable $(Y)$, the most influential being the assurance variable, the conclusion of the numbered hypothesis rejected and the null hypothesis accepted.

Conclusion: There is a significant influence between the quality of service and new concepts of customer comfort and customer satisfaction. This concept change succeeded even though it was reduced in terms of appearance but customers still felt satisfied with the quality of service.

Keywords: Quality of Service, Consumer Satisfaction, 3Store Ambasador

\section{Pendahuluan}

Era sekarang di dunia bisnis semakin tajam tidak hanya dari sisi produk tetapi perusahaan juga harus meningkatkan dari segi pelayanan. Produk sejenis sudah semakin banyak dijumpai dengan kualitas yang hampir mirip (Ali, Barusman, \& Oktavianur, 2019). Maka kunci yang utama adalah dari segi pelayanan. Kini pelayanan menjadi aspek paling terpenting dalam meningkatnya mutu perusahaan tersebut (Indriyani, 2020).

Menurut (Jamaluddin, 2016) bahwa pada pasca orde baru (era reformasi) umumnya pelayanan public di Indonesia masih belum memuaskan, sehingga diperlukan hadirnya komitmen yang lebih kuat lagi dari pada penyelenggara negara sebagai pihak yang diberi kewenangan sebagai servant untuk meningkatkan kinerja pelayanannya. Saat ini diyakini bahwa kunci utama dalam memenangkan persaingan bisnis adalah dengan memberikan kualitaspelayanan yang dapatmenciptakan kepuasanpelanggan (Harto, 2015).

Pelayanan yang memuaskan kepada pelanggan berlangsung saat pelanggan mendapatkanhasil yang baik dari kebutuhannya.

Bertahan atau tidaknya suatu perusahaan ditentukan oleh kemampuan perusahaan itu sendiri dalam memberikan pelayanan kepada pelanggannya, kepuasan pelanggan bisa menjadi senjata andalan untuk tampil sebagai pemenang dalam persaingan tetapi juga bisa sebaliknya, mejadi bumerang terhadap perusahaan itu sendiri (Ng \& Daromes, 2016).

Salah satu usaha yang H3I lakukan untuk meningkatkan kepuasan pelanggan melalui kualitas pelayanannya yaitu dengan mengadakan 3Store dengan konsep baru. Dan juga dengan model pelayanan yang baru ini sangat diharapkan dapat meningkatkan segi penjualan, dengan tujuan membuat pelanggan lebih nyaman mengujungi 3Store maka penjualan yang didapat akan lebih banyak pula (Mutia, 2017).

Perubahan konsep yang manajemen lakukan diharapkan dapat memperbaiki kualitas pelayanan dan meningkatkan kepuasan pelanggannya (Mukarom \& Laksana, 2015). Menurut (Astuti, Wilasari, \& Utami, 2012) dalam industri bisnis pelayanan 
memiliki peran yang cukup vital dalam mempertahankan loyalitas nasabah. Pelanggan yang puas akan pelayanan perusahaan akan berdampak positif terhadap perusahaan (Sembiring, 2014) bahkan hal tersebut menjadi indikator untuk menilai keberhasilan suatu perusahaan.

Berdasarkan uraian diatas maka penulis merumuskan beberapa permasalahan yang akan diteliti secara lebih mendalam, dapat dirumuskan sebagai berikut: (1) Apakah kualitas pelayanan berpengaruh terhadap kepuasan pelanggan di Hutchison 3 Indonesia? (2) Apakah kualitas pelayanan dengan konsep baru berpengaruh terhadap kenyamanan dan kepuasan pelanggan?.

\section{Metode Penelitian}

Metode yang digunakan di dalam penelitian ini adalah Descriptive yang didasarkan atas survei dengan pendekatan kuantitatif (Rukajat, 2018). yaitu penelitian yang menekankan pada pengujian teori-teori melalui pengukuran variabel-variabel penelitian dengan angka dan melakukan analisis data dengan prosedur statistik yang diolah dengan software SPSS versi 24 (Santoso, 2014).

1. Populasi Dan Sampel

Populasi dalam penelitina ini adalah pelanggan yang berkunjung ke 3Store Mall Ambasador dengan konsep baru yang sudah pernah ke 3Store lain sebelumnya sebanyak 981 di bulan Juli 2018. Dalam menentukan jumlah sampel minimum dalam penelitian ini didasarkan pada perhitungan Slovin dengan batas ketelitian 10\% dan didapat jumlah sampel minimum sebanyak 91 responden (Yudiaatmaja, 2013).

2. Teknik Pengumpulan Data

Observasi lapangan yaitu pengamatan dari peninjauan langsung objek yang diteliti di lapangan. Angket atau kuisioner, yaitu cara pengumpulan data dengan menyebarkan suatu daftar yang berisi serangkaian pertanyaan tertulis yang disusun secara sistematis yang diberikan kepada responden sebagai sampel penelitian ini. (Khumaeroh, Susongko, \& Rokhman, 2017).

\section{Tabel 1}

\section{Definisi Variabel Operasional}

\begin{tabular}{|c|c|c|c|}
\hline Variabel & Dimensi & Indik atơ & Skala Ukur \\
\hline \multirow{4}{*}{$\begin{array}{c}\text { Kualitas } \\
\text { Pelayanan }(X)\end{array}$} & Tangibles & Fas ilitas Fis ik, Perlengkapan, Pegawai & \multirow[t]{4}{*}{ Likert } \\
\hline & Responsiveness & $\begin{array}{l}\text { Kecepatan pelayanan, } 5 \text { kiap tanggap } \\
\text { petugas, pemberian pelayanan }\end{array}$ & \\
\hline & $\begin{array}{l}\text { Assurance } \\
\text { Emphaty }\end{array}$ & $\begin{array}{l}\text { Pengetahuan, kemampuan, kes opanan dan } \\
\text { sifat dapat diper caya } \\
\text { Kemudahan dalam melakuk an hubungan, } \\
\text { komunik asi yang baik }\end{array}$ & \\
\hline & Reliability & $\begin{array}{l}\text { Pemenuhan janji pelayanan yang tepat dan } \\
\text { memuaskan } \\
\text { Waktu dalam melavani }\end{array}$ & \\
\hline \multirow{4}{*}{$\begin{array}{c}\text { Kepuas an } \\
\text { Pelanggan }(Y)\end{array}$} & Kenyamanan & Ras a nyaman dalam dilayani & \multirow{4}{*}{ Likert } \\
\hline & Keramahan & Sikap pegawai saat melayani & \\
\hline & Ketepatan & Tepat menangani keluhan pelanggan & \\
\hline & Keamanan & Rasa aman menggunakan produk & \\
\hline
\end{tabular}

\section{Hasil dan Pembahasan}

Analisis Statistik meliputi:

1. Uji Validitas

Uji validitas adalah uji yang digunakan untuk menunjukkan sejauh mana alat ukur yang digunakan dalam suatu mengukur apa yang diukur. (Ghozali, 2018) 
menyatakan bahwa uji validitas digunakan untuk mengukur sah, atau valid tidaknya suatu kuesioner.

Tabel 2

Uji Validitas

\begin{tabular}{|c|c|c|c|}
\multirow{2}{*}{ Pernyataan } & \multicolumn{3}{|c|}{ Kualitas Pelayanan (X) } \\
\cline { 2 - 4 } & $\mathbf{r}_{\text {hitung }}$ & $\mathbf{r}_{\text {tabel } \mathbf{n}}=\mathbf{1 0 0}$ & Ket \\
\hline 1 & 0,270 & 0,129 & Valid \\
\hline 2 & 0,387 & 0,129 & Valid \\
\hline 3 & 0,176 & 0,129 & Valid \\
\hline 4 & 0,187 & 0,129 & Valid \\
\hline 5 & 0,393 & 0,129 & Valid \\
\hline 6 & 0,408 & 0,129 & Valid \\
\hline 7 & 0,409 & 0,129 & Valid \\
\hline 8 & 0,290 & 0,129 & Valid \\
\hline 9 & 0,243 & 0,129 & Valid \\
\hline 10 & 0,379 & 0,129 & Valid \\
\hline 11 & 0,403 & 0,129 & Valid \\
\hline 12 & 0,475 & 0,129 & Valid \\
\hline 13 & 0,374 & 0,129 & Valid \\
\hline 14 & 0,153 & 0,129 & Valid \\
\hline 15 & 0,249 & 0,129 & Valid \\
\hline
\end{tabular}

Sumber: Hasil Olahan Data (SPSS 24)

a. Uji Validitas Variabel Kualitas Pelayanan (X)

Berdasarkan tabel di atas, dapat dilihat bawa untuk masing-masing pernyataan pada variabel kualitas pelayanan (X) seluruh instrument dapat dikatakan valid, karena nilai rhitung yang dihasilkan lebih besar daripada nilai rtabel yang ada untuk $\mathrm{n}=100$ yaitu 0,129 .

b. Uji Validitas Variabel Kepuasan Pelanggan (Y)

\begin{tabular}{|c|c|c|c|}
\multirow{2}{*}{ Pernyataan } & \multicolumn{3}{|c|}{ Kepuasan Pelanggan $(\mathbf{Y})$} \\
\cline { 2 - 4 } & $\mathbf{r}_{\text {hitung }}$ & $\mathbf{r}_{\text {tabel }} \mathbf{n}=100$ & Ket \\
\hline 1 & 0,400 & 0,129 & Valid \\
\hline 2 & 0,324 & 0,129 & Valid \\
\hline 3 & 0,481 & 0,129 & Valid \\
\hline 4 & 0,357 & 0,129 & Valid \\
\hline 5 & 0,448 & 0,129 & Valid \\
\hline 6 & 0,465 & 0,129 & Valid \\
\hline 7 & 0,410 & 0,129 & Valid \\
\hline 8 & 0,465 & 0,129 & Valid \\
\hline 9 & 0,636 & 0,129 & Valid \\
\hline 10 & 0,391 & 0,129 & Valid \\
\hline
\end{tabular}

Sumber: Hasil Olahan Data (SPSS 24)

Pelanggan (Y) seluruh instrument dapat dikatakan valid, karena nilai rhitung yang dihasilkan lebih besar daripada nilai rtabel yang ada untuk $n=100$ yaitu 0,129 . 
2. Uji Reliabilitas

Menurut (Validitas, 2013) menyatakan bahwa reliabilitas menunjuk pada suatu pengertian bahwa instrumen yang digunakan dalam penelitian untuk memperoleh informasi yang digunakan dapat dipercaya sebagai alat pengumpulan data dan mampu mengungkap informasi yang sebenarnya dilapangan.

Tabel 4

Uji Reliabilitas Variabel Kualitas Pelayanan

\begin{tabular}{|r|r|}
\hline \multicolumn{2}{|c|}{ Reliability Statistic } \\
\hline Cronbach's Alpha & N of Items \\
\hline 0.602 & 15 \\
\hline
\end{tabular}

Sumber: Hasil Olahan Data (SPSS 24)

Berdasarkan tabel di atas, untuk uji reliabilitas variabel Kualitas Pelayanan (X) dengan nilai Cronbach's Alpha sebesar 0.602, sehingga dapat disimpulkan instrumen penelitian mengenai variabel kualitas Pelayanan (X) adalah Reliabel.

\section{Tabel 5}

Uji Reliabilitas Variabel Kepuasan Pelanggan

Reliability Statistic

\begin{tabular}{|r|r|}
\hline Cronbach's Alpha & N of Items \\
\hline 0.681 & 10 \\
\hline
\end{tabular}

Sumber: Hasil Olahan Data (SPSS 24)

Berdasarkan tabel di atas, untuk uji reliabilitas variabel Kepuasan Pelanggan (Y) dengan nilai Cronbach's Alpha sebesar 0.681, sehingga dapat disimpulkan instrumen penelitian mengenai variabel kualitas Pelayanan (X) adalah Reliabel.

\section{Tabel 6}

\section{Hasil Uji Normalitas data}

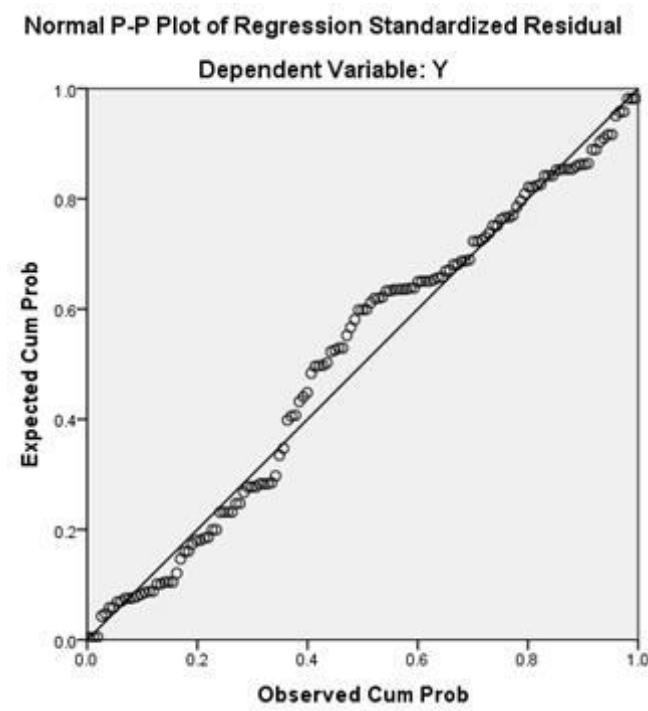

Sumber: Hasil Olahan Data (SPSS 24) 
Dari gambar di atas diketahui bahwa data berdistribusi normal. Hal ini dapat kita lihat dari penyebaran titk-titik obsservasi berada di sekitar garis prediktor.

Tabel 7

Hasil Uji Heteroskedastisitas data

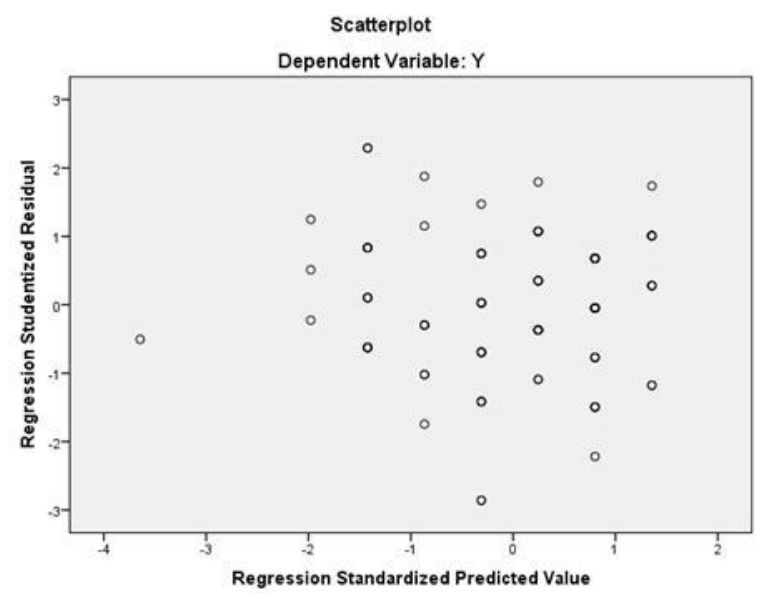

Dari output di atas dapat diketahui bahwa titik-titik tidak membentuk pola yang jelas, dan titik-titik menyebar di atas dan di bawah angka 0 pada sumbu Y. Jadi dapat disimpulkan bahwa tidak terjadi masalah heteroskedastisitas dalam model regresi

3. Uji Regresi Linier Sederhana

\section{Tabel 8}

\section{hasil uji regresi linear sederhana}

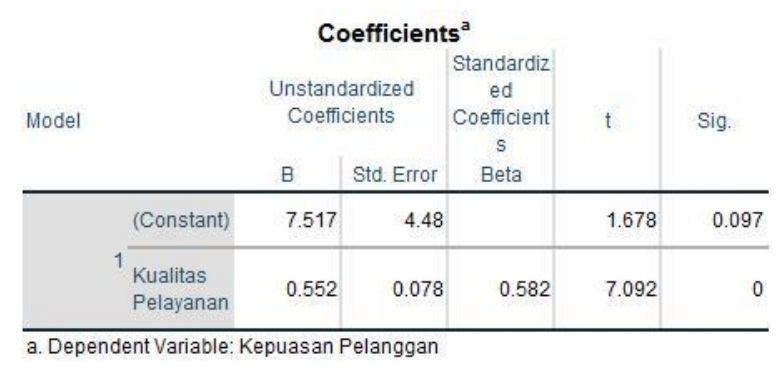

Dari hasil perhitungan pada tabel diatas dapat disajikan ke dalam bentuk persamaan regresi standardized sebagai berikut:

$$
\mathbf{Y}=\mathbf{7 , 5 7 1}+\mathbf{0 , 5 5 2} \mathrm{X} \text { Keterangan: }
$$

$\mathrm{Y}=$ Kepuasan Pelanggan $\mathrm{X}=$ Kualitas Pelayanan

Hasil persamaan regresi sederhana tersebut dapat dilihat bahwa koefisien regresi yang diperoleh bertanda positif. Hal tersebut menunjukkan bahwa variabel Kualitas Pelayanan akan meningkatkan kepuasan pelanggan untuk 3Store di Mall Ambasador,

4. Hasil Uji t

Variabel X yaitu kualitas pelayanan dengan thitung $(7.092)>t$ tabel $(1,66)$ dan Sig. $(0,000)<0,05$. Artinya variabel kualitas pelayanan konsep baru berpengaruh signifikan terhadap kepuasan pelanggan. 


\section{Kesimpulan}

Terdapat pengaruh signifikan antara kualitas pelayanan terhadap kepuasan pelanggan di 3Store Mall Ambasador. Adanya pengaruh secara signifikan antara kualitas pelayanan dengan konsep baru terhadap kenyamanan pelanggan dan kepuasan pelanggan. Perubahan konsep ini berhasil walaupun diperkecil dari segi tampilan tetapi pelanggan tetap merasa puas dengan kualitas pelayanannya. 


\section{DAFTAR PUSTAKA}

Ali, Firdaus, Barusman, Andala R. P., \& Oktavianur, M. (2019). Pengaruh Bauran Pemasaran dan Kualitas Pelayanan Terhadap Keputusan Pembelian Mobil Pada PT. Astra Internasional Daihatsu Lampung. VISIONIST, 8(1).

Astuti, Septin Puji, Wilasari, Wiwik, \& Utami, Datien Eriska. (2012). Meningkatkan Kualitas Pelayanan Di Bank Syariah Penelitian Dengan Fuzzy Servqual Dan Dimensi Carter. International Research Journal Of Business Studies, 2(1).

Ghozali, Imam. (2018). Aplikasi analisis multivariate dengan program IBM SPSS 25.

Harto, Budi. (2015). Analisis tingkat kepuasan pelanggan dengan pendekatan fuzzy servqual dalam upaya peningkatan kualitas pelayanan (studi kasus di bengkel resmi bajaj padang). Jurnal TeknoIf ISSN 2338-2724, 3(1).

Indriyani, Azizah. (2020). Manajemen Sdm Dalam Upaya Meningkatkan Mutu Dan Kualitas Pelayanan Di Ridwan Institute Cirebon. Syntax, 2(8).

Jamaluddin, Yanhar. (2016). Model Peningkatan Kualitas Pelayanan Publik. Jurnal Tapis: Jurnal Teropong Aspirasi Politik Islam, 12(1), 54-68.

Khumaeroh, Siti Umi, Susongko, Purwo, \& Rokhman, M. Shaefur. (2017). Penyusunan Skala Sikap Peserta Didik Terhadap Matematika dengan Penerapan Model Rasch. JPMP (Jurnal Pendidikan MIPA Pancasakti), 1(1).

Mukarom, Zaenal, \& Laksana, Muhibudin Wijaya. (2015). Manajemen pelayanan publik. Pustaka Setia.

Mutia, Shelia. (2017). Pengaruh Store Atmosphere Dan Kualitas Pelayanan Terhadap Loyalitas Pelanggan Pada Konsumen Di Resto Nanny's Pavillon Bandung. STIE Ekuitas.

Ng, Suwandi, \& Daromes, Fransiskus E. (2016). Peran kemampuan manajerial sebagai mekanisme peningkatan kualitas laba dan nilai perusahaan. Jurnal Akuntansi Dan Keuangan Indonesia, 13(2), 174-193.

Rukajat, Ajat. (2018). Pendekatan penelitian kuantitatif: quantitative research approach. Deepublish.

Santoso, Singgih. (2014). Panduan Lengkap SPSS versi 20 edisi revisi. Jakarta: PT. Elex Media Komputindo.

Sembiring, Inka Janita. (2014). Pengaruh Kualitas Produk Dan Kualitas Pelayanan Terhadap Kepuasan Pelanggan Dalam Membentuk Loyalitas Pelanggan (Studi Pada Pelanggan Mcdonald's Mt. haryono Malang). Brawijaya University.

Validitas, Uji. (2013). Reliabilitas. Hasil Uji Validitas Dan Reliabilitas Variabel X, 2.

Yudiaatmaja, Fridayana. (2013). Analisis Regresi Dengan Menggunakan Aplikasi Komputer Statistik. Gramedia Pustaka Utama. 